\title{
Progranulin antibodies entertain a proinflammatory environment in a subgroup of patients with psoriatic arthritis
}

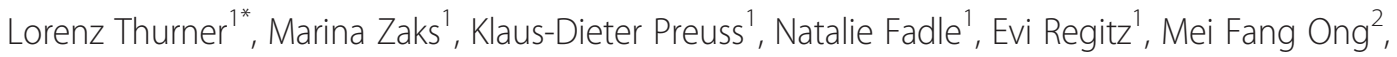
Michael Pfreundschuh ${ }^{1}$ and Gunter Assmann ${ }^{1}$

\begin{abstract}
Introduction: Psoriatic arthritis (PsA) is a distinctive inflammatory arthritis which may typically develop in a subgroup of individuals suffering from psoriasis. We recently described progranulin autoantibodies (PGRN-Abs) in the sera of patients with different autoimmune diseases including seronegative polyarthritis. In the present study we investigated the occurrence of PGRN-Abs in PsA.
\end{abstract}

Methods: PGRN-Abs were determined in 260 patients with PSA, 100 patients with psoriasis without arthritic manifestations ( $\mathrm{PsC}$ ) and 97 healthy controls using a recently described ELISA. PGRN plasma levels were determined from subgroups by a commercially available ELISA-kit. Possible functional effects of PGRN-antibodies were analysed in vitro by tumour necrosis factor (TNF)-a mediated cytotoxicity assays using WEHI-S and HT1080 cells.

Results: PGRN-Abs were detected with relevant titres in 50/260 (19.23\%) patients with PsA, but in 0/100 patients with psoriasis without arthritic manifestations ( $P=0.0001$ ). All PGRN-Abs belonged to immunoglobulin $\mathrm{G}(\mathrm{IgG})$. PGRN-Abs were significantly more frequent in PsA patients with enthesitis or dactylitis. PGRN-Abs were also more frequent in PSA patients receiving treatment with TNF-a-blockers than in patients treated without TNF-a-blockers (20.8\% versus $17.4 \% ; P=0.016)$. PGRN plasma levels were significantly lower in PGRN-Ab-positive patients with PsA than in healthy controls and patients with psoriasis without arthritic manifestations $(P<0.001)$, indicating a neutralizing effect of PGRN-Abs. Moreover cytotoxicity assays comparing PGRN-antibody positive with negative sera from matched patients with PSA, clearly showed a proinflammatory effect of PGRN antibodies.

Conclusion: Neutralizing PGRN-Abs occur with relevant titres in a subgroup of patients with PsA, but not in patients without arthritic manifestations (PsC). PGRN-Ab-positive patients had more frequent enthesitis or dactylitis. TNF-a-induced cytotoxicity assays demonstrated that the protective effects of progranulin were inhibited by serum containing PGRN-Abs. This suggests that PGRN-Ab might not only be useful as a diagnostic and prognostic marker, but may provide a proinflammatory environment in a subgroup of patients with PsA.

\section{Introduction}

Psoriatic arthritis (PsA) is a distinctive inflammatory form of arthritis that may develop in $20 \%$ to $25 \%$ of individuals with psoriasis [1]. In addition to manifestations of psoriasis in the skin, patients with PsA may present with mild to very severe development of oligoarthritis

\footnotetext{
* Correspondence: Lorenz.Thurner@uks.eu

'Department of Internal Medicine I, José Carreras-Center for Immuno- and Gene Therapy, University of Saarland Medical School, Kirrbergerstr., D-66421 Homburg, Saar, Germany

Full list of author information is available at the end of the article
}

and/or polyarthritis, enthesitis, dactylitis or axial skeletal manifestations similar to spondyloarthritis. PsA has been considered a seronegative inflammatory arthritis according to the diagnostic criteria first published by Moll et al. in 1973 [2] and then redefined by the Classification Criteria for Psoriatic Arthritis (CASPAR) [3]. All definitions of PsA have in common the seronegative status of the disease because autoantibodies (Abs) such as rheumatoid factor (RF), anticyclic citrullinated autoantibodies and antinuclear autoantibodies are usually absent in PsA. Hence, in contrast to rheumatoid arthritis, autoreactive B

\section{Ciomed Central}

(c) 2013 Thurner et al.; licensee BioMed Central Ltd. This is an open access article distributed under the terms of the Creative Commons Attribution License (http://creativecommons.org/licenses/by/2.0), which permits unrestricted use, distribution, and reproduction in any medium, provided the original work is properly cited. 
lymphocytes are believed to play only a minor role in PsA [4]. Regarding the occurrence of autoantibodies in PsA, increased frequencies of thyreoglobulin Abs (14.29\%) and thyroid peroxidase Abs (23\%) were reported in PsA, which was explained by a relatively high comorbidity rate, with $26 \%$ of patients with PsA having autoimmune thyroiditis [5]. In another study, 20S proteasome autoantibodies were more frequently detected in PsA patients $(27.8 \%)$ than in in healthy controls $(0 \%)$, as well as more frequently in systemic lupus erythematosus patients (42\%) than in rheumatoid arthritis patients (5\%) [6]. However, the numbers of patients were small in these studies (36 PsA patients and 30 healthy controls) [6], and, in both studies, no patients with psoriasis without arthritic manifestations (PsC) were included. To date, no specific serological markers discriminating patients with PsA from patients with $\mathrm{PsC}$ have been identified. Nevertheless, a small but significant occurrence of B lymphocytes was reported in the skin of patients with PsA, but not in patients with PsC [7].

Recently, we discovered progranulin autoantibodies (PGRN Abs) in a protein array-based screening of plasma from various primary vasculitides and found evidence that these PGRN Abs have a neutralizing effect on PGRN plasma levels [8]. PGRN is a secreted precursor protein that is cleaved at the linker regions between individual granulins by neutrophil elastase [9], proteinase 3 [10], matrix metalloproteinase 12 [11], matrix metalloproteinase 14 [9] and ADAMTS-7 (a disintegrin and metalloprotease with thrombospondin motif 7) [12]. Until recently, most research on PGRN had focused on its role in neurodegenerative diseases such as frontotemporal lobe dementia [13]. However, since Tang et al. [14] showed that PGRN is a high-affinity ligand of the tumour necrosis factor $\alpha$ (TNF- $\alpha$ ) receptors 1 and 2 (TNFR1 and TNFR2) and that its anti-inflammatory effect is caused by direct inhibition of these receptors, PGRN has increasingly become the focus of research on autoimmune diseases.

Recently, Chen et al. [15] challenged the notion of this interaction of PGRN with TNFR1 and TNFR2 previously reported by Tang et al. [14], as they could not reproduce the interaction of PGRN with TNFR1 and TNFR2. However, they did not question the anti-inflammatory effect of PGRN [10]. Tang et al. responded in a letter to the editor that Chen et al. utilized PGRN, which might be folded improperly. Furthermore, Tang et al. stated that validation of recombinant PGRN's functionality based only on its C-terminal binding to sortilin would be insufficient to determine its quality regarding its other biological functions, which are not primarily mediated by PGRN's C-Terminus. Subsequently, Jian et al. showed in detail that PGRN binds as TNF- $\alpha$ to cysteine-rich domain 2 (CRD2) and CRD3 of TNFR and that proper folding of PGRN is essential for this binding. Furthermore, dithiothreitol treatment of PGRN, which had been performed by Chen et al., abolishes the binding of PGRN to TNFR but enhances its binding to sortilin [16]. Recently, two other groups independently reproduced the binding of PGRN to TNFR1 and TNFR2, and inhibitory effect of this binding on TNF- $\alpha$-induced effects $[17,18]$. Dramatic effects of PGRN deficiency have been shown in vivo in collageninduced arthritis and collagen Ab-induced arthritis mouse models, resulting in fulminant courses of disease [14]. Furthermore, the administration of recombinant human PGRN or a recombinant PGRN derivative, antagonist of TNF/ TNFR signalling via targeting to TNF receptors (ATSTTRIN), that consists of three modified granulin motifs and their accompanying linker regions [14] had strong anti-inflammatory effects comparable to, or even stronger than, the administration of etanercept [14]. Consequently, PGRN and ATSTTRIN have been regarded as promising nextgeneration TNF- $\alpha$ blockers [19]. In addition to this strong anti-inflammatory effect mediated by the inhibition of TNFR1 and TNFR2, several other functions of PGRN in humans have been reported [20].

Interestingly, the previously detected PGRN Abs showed neutralizing effects on PGRN plasma levels detected by enzyme-linked immunosorbent assay (ELISA) and Western blot analysis. This observation, given the anti-inflammatory properties of secreted PGRN, suggested a proinflammatory effect of PGRN Abs, which was supported by our observation that the presence of PGRN Abs is associated with active disease state in granulomatosis with polyangiitis [8]. Apart from primary systemic vasculitis, we also found neutralizing PGRN Abs in systemic lupus erythematosus as well as in rheumatoid arthritis [8]. Some of the rheumatoid arthritis patients with PGRN Abs were actually seronegative for RF or anticitrullinated protein Abs. Furthermore, PGRN Abs were detected in patients with spondyloarthritis. This observation led us to conduct the present study to investigate the presence of PGRN Abs in patients with the seronegative disorder PsA, compare it to patients with $\mathrm{PsC}$ and healthy controls and investigate possible functional effects of PGRN Abs in vitro.

\section{Methods}

\section{Study participants}

This study was approved by our regional ethical review committee (Ethikkommission der Ärztekammer des Saarlandes) and conducted according to the Declaration of Helsinki. Serum samples of patients with PsA were collected prospectively from patients attending three centres of rheumatology between October 2011 and July 2012: Saarland Rheumatology Centre, the Department of Internal Medicine I at University Hospital in Homburg/ 149 Saar, the Rheumatology Department of the University Hospital Frankfurt am Main and the Outpatient Center for Rheumatology in Berlin-Lichtenberg. Sera from patients with PsC were provided by the Department of Dermatology of 
Saarland University Medical School. Serum samples taken from healthy controls were also obtained at Saarland University Medical School. All serum specimens were stored at $-80^{\circ} \mathrm{C}$ at the Department of Internal Medicine I, José Carreras Research Centre, Saarland University Medical Centre. All patients were examined by a rheumatologist (PsA patients) and a dermatologist (PsC patients) to confirm the diagnosis of PsA according to the CASPAR criteria or to exclude PsA in PsC patients. All diagnoses of $\mathrm{PsC}$ were made by dermatologists and confirmed by a rheumatologist. All PsA patients were stratified into subgroups according to gender, age, presence or absence of manifestations of axial disease, enthesitis, dactylitis and therapeutic regimens such as TNF- $\alpha$ blocker-containing medication. Axial disease was defined by positive findings on X-rays or magnetic resonance imaging scans for spondyloarthritis and/or sacroiliitis. Patients were considered positive for enthesitis or dactylitis on the basis of a positive diagnosis during the course of disease; however, no imaging findings have been required. No subgroup stratification for patients with PsC was performed, because the PGRN Ab serostatus of all patients with PsC was negative. All patients and healthy controls gave their written informed consent to participate in the study.

\section{Progranulin antibody enzyme-linked immunosorbent assay}

The ELISA for PGRN Abs was performed as previously described [8]. In short, the GRN gene encoding PGRN was recombinantly expressed with a C-terminal FLAG-tag in HEK293 cells under the control of a cytomegalovirus promoter (pSFI). Total cell extracts were prepared and bound to Nunc MaxiSorp plates (eBioscience, Frankfurt, Germany) precoated with murine anti-FLAG mAb at a dilution of 1:2,500 (v/v; Sigma-Aldrich, Munich, Germany) at $4{ }^{\circ} \mathrm{C}$ overnight. Blocking was performed with $1.5 \%(\mathrm{w} / \mathrm{v})$ gelatin in Tris-buffered saline (TBS), and washing steps were performed with TBS with Triton X-100. The individual serum samples were diluted 1:100. ELISA was performed according to standard protocols with the following Abs: biotinylated goat antihuman heavy and light chain immunoglobulin G (IgG) at a dilution of 1:2,500 (Dianova, Hamburg, Germany); subclass-specific sheep antihuman IgG1, IgG2, IgG3 and IgG4 (Binding Site Group, Birmingham, UK) at dilutions of 1:5,000; goat antihuman IgM (Dianova) at a dilution of 1:2,500; or goat antihuman IgA (Dianova) at a dilution of 1:2,500. Following this step, corresponding biotinylated secondary Abs were used for immunoassays carried out to detect IgG subclasses and IgM. Peroxidase-labelled streptavidin (Roche Applied Science, Indianapolis, IN, USA) was used at a dilution of 1:50,000. As a cutoff for positivity, the average of the optical density (OD) of the negative samples plus three standard deviations was applied.

\section{Progranulin plasma levels measured by enzyme-linked immunosorbent assay}

PGRN plasma levels were determined with a commercially available ELISA kit (AdipoGen, Incheon, South Korea) according to the manufacturer's instructions. The median of the plasma PGRN level of the healthy control group was set at $100 \%$ [8].

\section{Cytotoxicity assay}

A nonradioactive cytotoxicity assay (EZ4U Cell Proliferation Assay; Biomedica, Vienna, Austria) was performed according to the manufacturer's instructions. For this TNF- $\alpha$-induced cytotoxicity assay, we used the highly TNF- $\alpha$-sensitive mouse fibrosarcoma WEHI-S cell line as the target cells [21]. The interaction of human recombinant PGRN with murine TNFR1 and TNFR2 was previously demonstrated in vitro and in vivo [14], and, moreover, human PGRN Abs bind murine PGRN (Additional file 1). As a human control target cell line, the TNF- $\alpha$-sensitive HT-1080 fibrosarcoma cell line was used.

In short, $4 \times 10^{4}$ WEHI-S cells or $4 \times 10^{4} \mathrm{HT}-1080$ cells were seeded into $200 \mu \mathrm{l}$ of cell culture at $37^{\circ} \mathrm{C}$ and $5 \% \mathrm{CO}_{2}$. To detect possible differences between added sera of patients with PsA with and without PGRN Abs, of patients with $\mathrm{PsC}$, and of healthy controls, serum of a PGRN Ab-positive patient with PsA, serum of a matched PGRN Ab-negative patient with PsA, serum of a patient with $\mathrm{PsC}$ and serum of a healthy control were added in dilutions from 1:4 to 1:512 to cultured WEHI-S cells and HT-1080 cells, followed by administration of TNF- $\alpha$ (100 pg/ml). Serum samples from gender-, age-, diseaseand therapy modality-matched patients were chosen. Serum samples from patients receiving TNF- $\alpha$ blockers or other biologicals were excluded. WEHI-S cells and HT-1080 cells without addition of TNF- $\alpha$ and serum, or solely with addition of TNF- $\alpha(100 \mathrm{pg} / \mathrm{ml})$, were used as positive and negative controls. After 24-hour incubation at $37^{\circ} \mathrm{C}, 20 \mu \mathrm{l}$ of chromophore substrate were added to each well. This chromophore substrate is converted only by vital cells. The adsorption of the product was measured at an OD of $450 \mathrm{~nm}$.

\section{Statistical analyses}

Differences in age and gender between the populations of PsA patients, PsC patients and healthy controls were tested by Student's $t$-test. Different frequencies of PGRN Abs in the serum samples of patients with PsA and PsC were analysed by $\chi^{2}$ test. Differences in the frequency of PGRN Abs between PsA patients after stratification into subgroups were also tested with the $\chi^{2}$ test. For analysis of the differences in PGRN plasma levels between healthy controls, PGRN Ab-positive and PGRN Ab-negative patients with PsA and seronegative patients with PsC, the Mann-Whitney $U$ test was applied. A two-sided test value 
less than 0.05 was considered statistically significant. All statistical analyses were performed in SPSS version 19.0 for Windows software (IBM SPSS, Chicago, IL, USA).

\section{Results}

Patient characteristics

The patients' characteristics are outlined in Table 1.

\section{Frequency, titres and immunoglobulin $G$ subclass of progranulin antibodies}

Of 260 patients with PsA, 50 (19.23\%) had PGRN Abs in their sera. No PGRN Abs were found in the sera of 100 patients with $\mathrm{PsC}(0 \% ; P=0.0001)$. Of 97 healthy controls, 1 (1.03\%) had PGRN Abs (Figure 1a). PGRN Ab-positive patients had titres ranging from 1:400 to 1:1,600 (Figure 1b). The sera of the 50 PGRN Abpositive PsA patients were tested for their Ig class. PGRN Abs belonged exclusively to IgG (50 of 50 patients). PGRN Abs were not detected for either IgA or IgM (Additional file 1). Subsequently, IgG subclasses of PGRN Abs were determined. The PGRN Abs in 44 patients $(88 \%)$ belonged to the IgG1 subclass, $1(2 \%)$ of 50 belonged to the IgG2 subclass, 5 (10\%) 50 belonged to the IgG3 subclass and $0(0.0 \%)$ of 50 belonged to the IgG4 subclass (Figure 1c).

\section{Analysis of the progranulin-positive patients with psori- atic arthritis}

All 260 PsA patients (210 PGRN Ab-negative, 50 PGRN Ab-positive) were stratified according to their clinical manifestations, such as enthesitis, dactylitis, axial manifestations and erosive-proliferative joint damage. Patients with PsA were also analysed in subgroups according to age at primary diagnosis, gender, human leucocyte antigen B27 status and treatment with TNF- $\alpha$-blocking agents

Table 1 Characteristics of patients with psoriatic arthritis and psoriasis without arthritis

\begin{tabular}{|c|c|c|}
\hline Characteristics & PsA & PsC \\
\hline Median age (min-max) & $54(24-81)$ & $53(16-80)$ \\
\hline Gender, M/F (\%) & $43.5 / 56.4$ & $64 / 36$ \\
\hline Age at psoriasis diagnosis, years & 35 & 33 \\
\hline Age at PsA diagnosis, years & 46 & \\
\hline Enthesitis (\%) & 39.5 & \\
\hline Dactylitis (\%) & 39.2 & \\
\hline Axial disease (\%) & 27.7 & \\
\hline Erosive $(\%)^{b}$ & 44.9 & \\
\hline HLA-B27-positive (\%) & 32.7 & \\
\hline $\operatorname{DMARD}(\%)^{\mathrm{c}}$ & 48.8 & \\
\hline TNF-a blockers (\%) & 18.4 & \\
\hline
\end{tabular}

DMARD: disease-modifying antirheumatic drug; HLA-B27: human leucocyte antigen B27; PsA: psoriatic arthritis; PSC: psoriasis without arthritic manifestations; TNF-a: tumour necrosis factor a. Missing data: ${ }^{a} n=69,{ }^{b} n=24,{ }^{c} n=29,{ }^{d} n=9$.
(Figure 2). Although there was no difference between PGRN Ab-positive and PGRN Ab-negative patients with respect to age at the time of PsA diagnosis, PGRN Abpositive patients were significantly older ( $>50$ years) than PGRN Ab-negative patients with PsA (21\% vs. $15.4 \%$; $P=$ 0.016). PsA patients with either enthesitis or dactylitis had significantly higher frequencies of PGRN Abs $(P=0.001$ and $P=0.026$, respectively, compared to patients with PsA without enthesitis or dactylitis), whereas no statistically significant associations were found for axial manifestations or erosive joint destruction and PGRN Ab positivity. In addition, significantly more patients receiving TNF- $\alpha$ blocker treatment had PGRN Abs compared to patients receiving therapy without TNF- $\alpha$ blockers $(20.8 \%$ vs. $17.4 \% ; P=0.016)$.

\section{Progranulin plasma levels}

PGRN plasma levels were significantly lower in PGRN Ab-positive patients with PsA $(n=10)$ compared to healthy controls $(n=10)(P<0.001$ by Mann-Whitney $U$ test $)$, patients with $\operatorname{PsC}(n=10)(P<0.001$ by MannWhitney $U$ test) and PGRN Ab-negative patients with PsA $(n=5)(P<0.001$ by Mann-Whitney $U$ test). Furthermore, PGRN Ab-negative patients with PsA had significantly lower plasma levels of PGRN than healthy controls $(P=0.019$ by Mann-Whitney $U$ test). There was also a tendency toward lower PGRN plasma levels in PGRN Ab-negative patients with PsA than in patients with PsC $(P=0.055$ by Mann-Whitney $U$ test) (Figure 3$)$.

\section{Cytotoxicity assay}

In the TNF- $\alpha$-induced cytotoxicity assays, we analysed the protective effects of sera from healthy controls, patients with PsC and PGRN Ab-positive or PGRN Abnegative patients with PsA. The addition of sera from healthy controls, patients with PsC and PGRN Ab-negative patients with PsA reduced TNF- $\alpha$-induced cytotoxicity of WEHI-S and HT-1080 cells to a significantly higher degree than in the sera of PGRN Ab-positive patients with PsA. This difference was significant up to a serum dilution of 1:64 (Figures 4a and 4b).

\section{Discussion}

In the present study, we report the presence of PGRN Abs in relevant titres in a subgroup of patients with PsA (Figures 1a and b). These PGRN Abs had previously been found frequently in primary vasculitis, systemic lupus erythematosus and rheumatoid arthritis, but not at all or very infrequently in controls. Despite the obvious lack of specificity for PsA, PGRN Abs are of particular interest because they had a neutralizing effect on PGRN plasma levels detected by ELISA and Western blot analysis [8]. PGRN is known to be a strong secreted anti-inflammatory mediator [10] by direct inhibition 


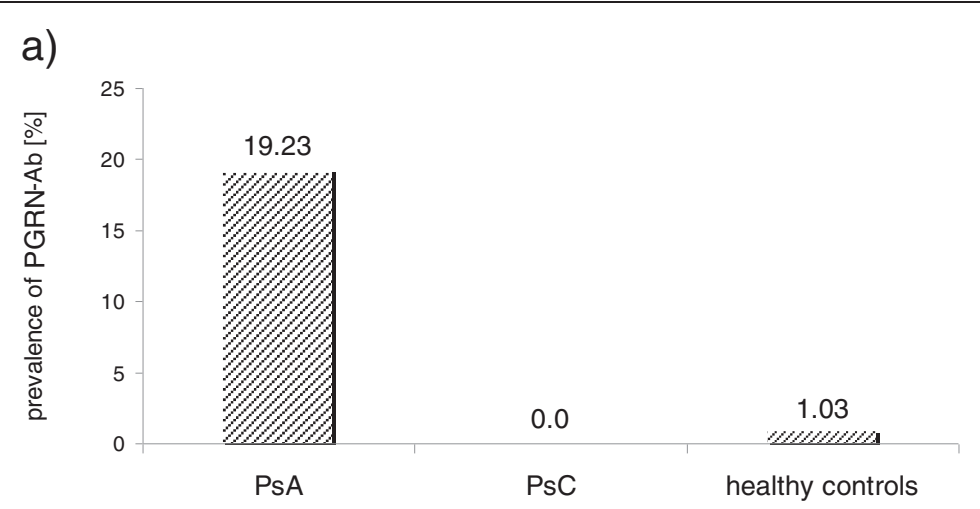

b)

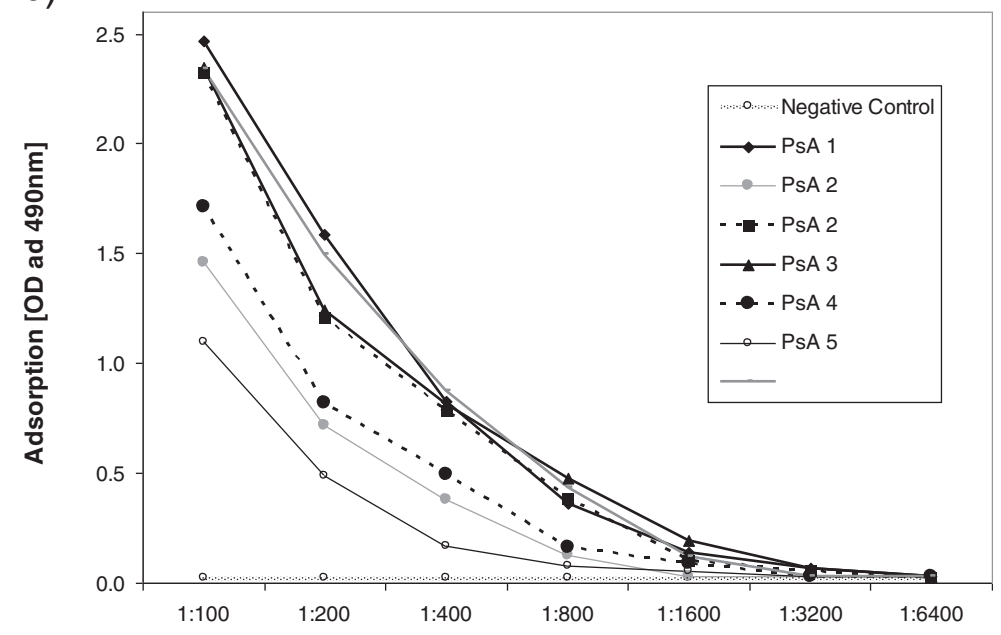

c)

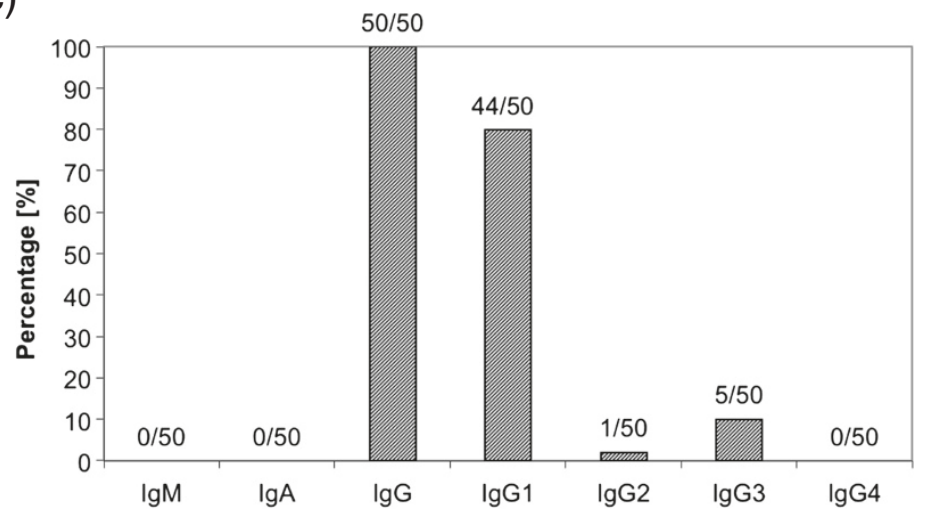

Figure 1 Occurrence of progranulin antibodies in psoriatic arthritis patients. (a) Prevalence of progranulin antibodies (PGRN Abs) in psoriatic arthritis (PSA) patients. (b) Titres of PGRN Abs in PSA patients. (c) Frequency of different immunoglobulin classes of PGRN Abs in PSA patients. Ig: immunoglobulin; OD, optical density; PsC: psoriasis without arthritic manifestations.

of TNFR1 and TNFR2 [14]. Our results support the hypothesis of a proinflammatory effect of PGRN Abs, as demonstrated by the loss of protective effects of PGRN in the presence of PGRN Abs containing PsA sera in TNF- $\alpha$-mediated cytotoxicity assays (Figures 4a and $4 \mathrm{~b}$ ). Our results support the observation by Tang et al. of a direct inhibitory effect of PGRN on TNFR1 and TNFR2 and that administration of recombinant human PGRN protects cells from cytotoxic effects of TNF- $\alpha$ in vitro $[14,16]$. Given the fact that the halflife of PGRN is about 40 hours [14], in contrast to the short half-life of TNF- $\alpha$ (typical for cytokines) of 20 minutes [22], the effects of the intrinsic TNF- $\alpha$ in the serum of patients and controls is negligible. Our cytotoxicity assays revealed clear differences between the effects of serum from PGRN Ab-positive patients 


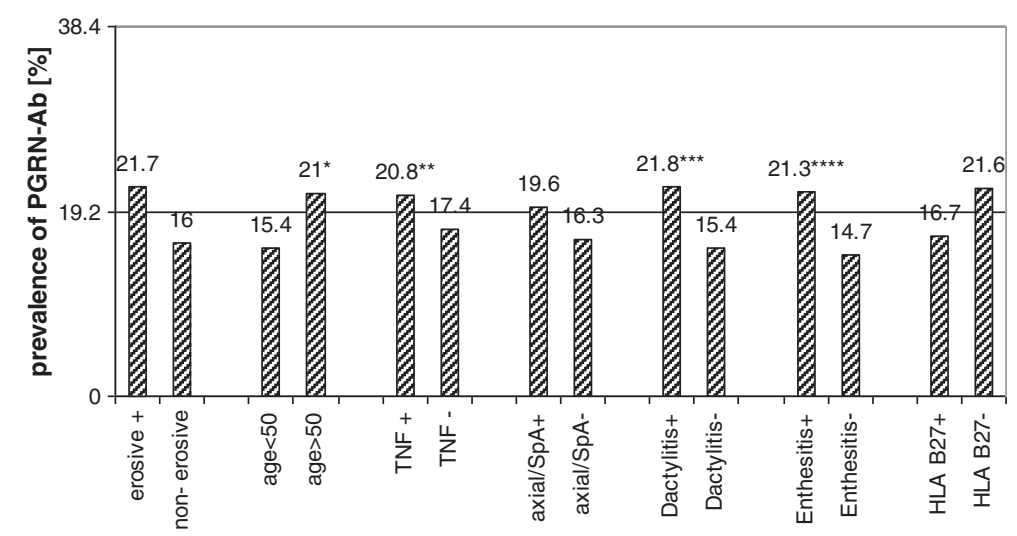

Figure 2 Progranulin antibodies in subpopulations of patients with psoriatic arthritis. The columns represent the percentage of progranulin antibody (PGRN Ab)-positive patients in different subgroups of psoriatic arthritis (PSA) compared to the average frequency of PGRN Abs in PsA patients (19.23\%; horizontal line). HLA-B27: human leucocyte antigen B27; SpA: spondyloarthritis; TNF: tumour necrosis factor. ${ }^{*} P=0.016,{ }^{* *} P=0.001,{ }^{* *} P=0.026,{ }^{* * *} P=0.001$.

with PsA on the one hand and serum from matched PGRN Ab-negative patients with PsA, patients with PsC or healthy controls on the other hand. The administration of serum samples of patients with PsA with neutralizing PGRN Abs, and thus with lower PGRN levels, protected the WEHI-S and HT-1080 cells from the cytotoxic effects of TNF- $\alpha$ far less than serum samples from patients with PsA without PGRN Abs, patients with PsC or healthy controls. This finding clearly proves the proinflammatory effect of neutralizing PGRN Abs in vitro.
The second important finding of the present study is that PGRN Abs were observed in patients with PsA, but not in patients with $\mathrm{PsC}$ (Figure 1). Interestingly, Veale et al. reported small but significant numbers of B cells in the skin of patients with PsA, but not in the skin of patients with $\mathrm{PsC}$ or in healthy controls [7]. In the present study, the occurrence of PGRN Abs in patients with PsA was associated with different clinical characteristics. PsA patients with dactylitis and enthesitis had PGRN Ab more frequently than PsA patients without such manifestations. Moreover, patients with PsA who

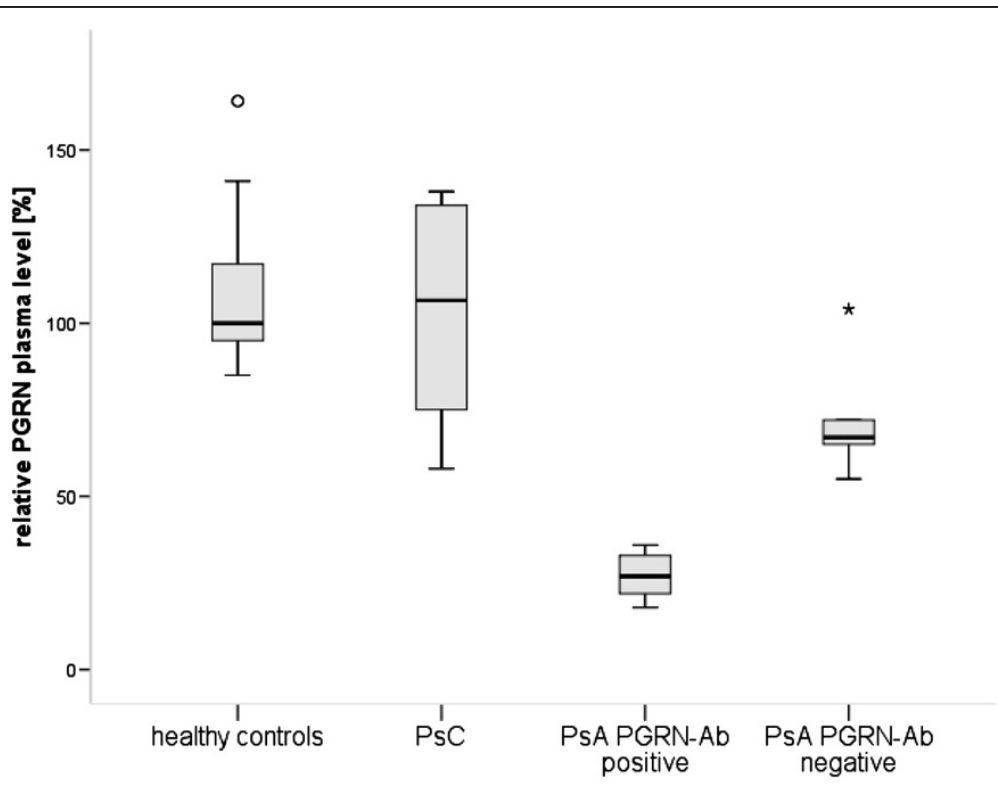

Figure 3 Association of progranulin antibody status and progranulin plasma levels in psoriasis patients. Progranulin (PGRN) plasma levels were determined in patients with psoriasis without arthritic manifestations (PsC) $(n=10)$, PGRN antibody (PGRN Ab)-positive patients with psoriatic arthritis (PSA) $(n=10)$, PGRN Ab-negative patients with PSA $(n=5)$ and in healthy controls $(n=10)$. Data are presented as $25 \%$ (box), $50 \%$ (median) and 75\% (box) percentiles and the range (line). Median PGRN plasma level obtained from healthy controls was set at 100\%. 

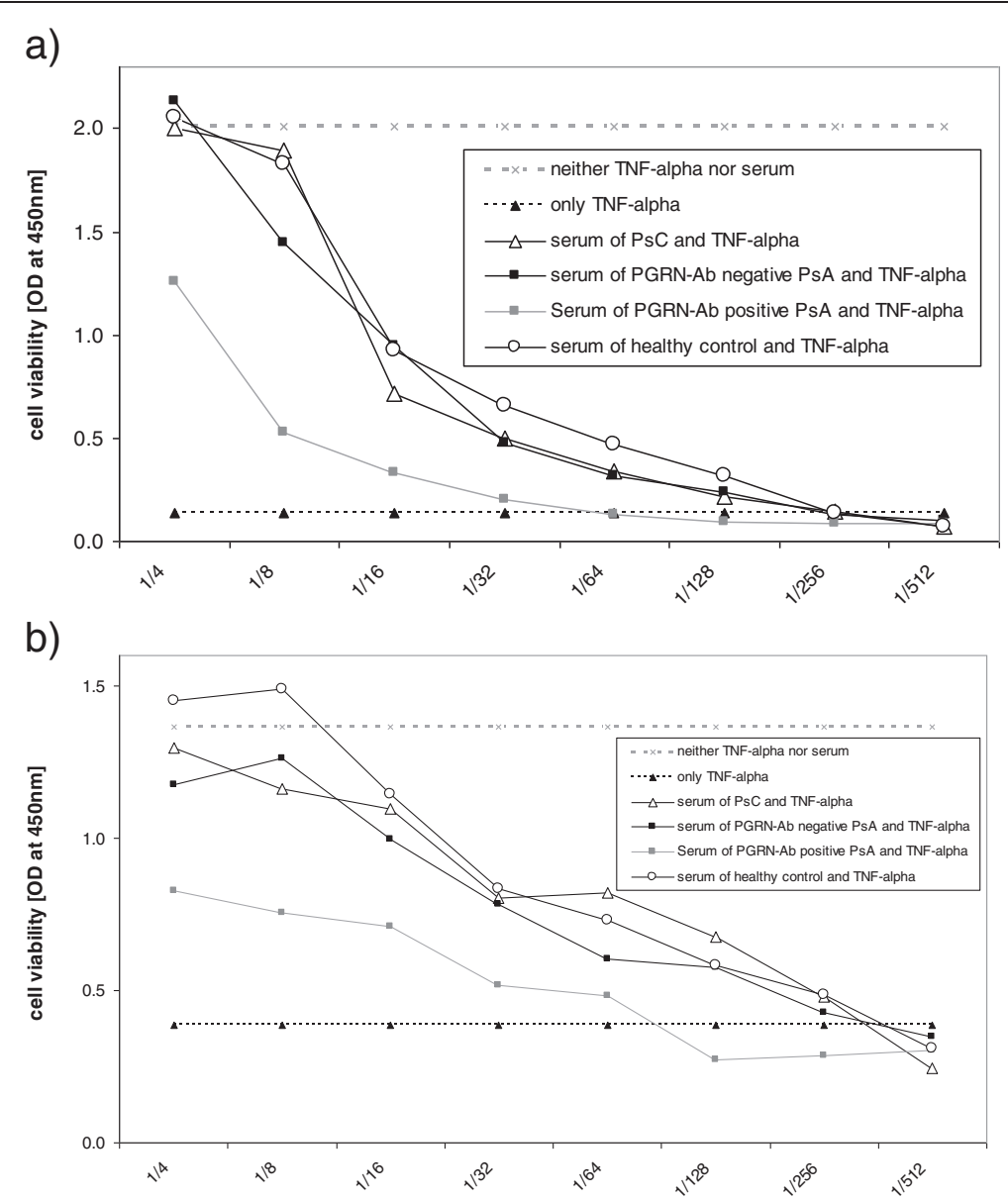

Figure 4 Tumour necrosis factor a-mediated cytotoxicity dependent on progranulin antibody status. (a) After administration of serum and TNF-a to WEHI-S cells, the adsorption of coloured formazan, which is a marker for cell viability, was detected at OD of $450 \mathrm{~nm}$. (b) After administration of serum and TNF-a to HT-1080 cells, the adsorption of coloured formazan was detected at OD of 450 nm. Ab: antibody; PGRN: progranulin; PsA: psoriatic arthritis; PsC: psoriasis without arthritic manifestations.

received TNF- $\alpha$ blocker therapy for at least 3 months had PGRN Abs slightly more frequently (20.8\% versus 17.4\%), indirectly suggesting that PGRN Abs might be associated with a more aggressive course of disease, necessitating more intensive treatment. Generally, the grades of dactylitis and enthesitis in PsA patients have been suggested to be partly influenced, that is, enhanced, by TNF- $\alpha$, which is supported by the efficacy of TNF- $\alpha$ blockers in PsA therapy [23-26]. Given the neutralizing effect of PGRN Abs on PGRN plasma levels in PsA patients (Figure 3), as well as in other autoimmune diseases [8], and, more important, given the results of the functional in vitro assays indicating a sensitizing effect of PGRN Abs for the effects of TNF- $\alpha$ in patients with PsA, a higher prevalence of PGRN Abs in patients with TNF- $\alpha$-induced disease manifestations such as enthesitis and dactylitis could obviously be expected. Despite the statistical significance of our results, however, the relative differences in the frequency of PGRN Abs between the various subgroups were rather small (PGRN Ab-positive enthesitis $21.3 \%$ vs. PGRN Ab-negative enthesitis $14.7 \%$ and PGRN Ab-positive dactilytis 21.8\% vs. PGRN Ab-negative enthesitis 15.4\%). These results could be explained by the relatively small absolute numbers of patients with subentities and partly by missing data concerning dactylitis and enthesitis. Moreover, we observed a statistically nonsignificant trend between the occurrence of PGRN Abs and the presence of erosive joint disease $(P=0.061)$. In consideration of the suspected pathogenic proinflammatory effect of PGRN Abs disrupting the physiologic homeostasis of TNF- $\alpha /$ PGRN agonists and antagonists in a subgroup of patients with PsA, PGRN Abs might be of use as prognostic markers for the course of disease and/or as predictive markers for the effectiveness of TNF- $\alpha$-blocking agents. Theoretically, the identification of neutralizing PGRN Abs in 
PsA could eventually lead to a more individualized therapy because patients with PGRN Abs have lower physiologic TNF- $\alpha$ antagonist levels and might profit from dose intensification of TNF- $\alpha$ blockers. From this point of view, prospective studies of patients with PsA are needed to evaluate PGRN Abs as possible biomarkers for the diagnosis, risk stratification and choice of adequate treatment modality.

\section{Conclusion}

Neutralizing PGRN Abs occurred in relevant titres in a subgroup of patients with PsA, but not in PsC patients. PGRN Ab-positive patients with PsA had more frequently enthesitis and dactylitis than PGRN Ab-negative patients with PsA. Moreover in TNF- $\alpha$-induced cytotoxicity assays using WEHI-S and HT-1080 cells, the protective effects of PGRN were inhibited by PGRN Abcontaining sera of patients with PsA. This suggests that PGRN Abs not only may be useful as a diagnostic and prognostic marker but also may be involved in the pathogenesis of the arthritic process in a subgroup of patients with PsA.

\section{Additional file}

Additional file 1: Figure S1. Immunoglobulin class of progranulin (PRGN) antibodies (Abs) in psoriatic arthritis. Each PGRN Ab-containing serum was tested for immunoglobulin (lg) class of PGRN Abs. (a) PGRN Abs were tested for lgG class. (b) PGRN Abs were tested for IgA class. (c) PGRN Abs were tested for lgM class. (d) PGRN Abs were tested for lgG1 subclass. (e) PGRN Abs were tested for lgG2 subclass. (f) PGRN Abs were tested for lgG3 subclass. (g) PGRN Abs were tested for lgG4 subclass. Sera were used at a dilution of 1:100.

\section{Abbreviations}

Ab: Antibody; IgG: Immunoglobulin G; PGRN: Progranulin; PsA: Psoriatic arthritis; PsC: Psoriasis without arthritic manifestations; TNF-a: Tumour necrosis factor a; TNFR: Tumour necrosis factor receptor.

\section{Competing interests}

Saarland Universities Patent Marketing Agency, LT, KDP and MP filed 61/ 730,772 , which covers means and methods for detecting autoimmune disorders in which progranulin may be involved.

\section{Authors' contributions}

$M Z, N F$ and ER performed most of the experiments and were involved in data analysis. LT, MP and GA were involved in the study design and data analysis and drafted the manuscript. MFO was involved in data analysis. All authors read and approved the final manuscript.

\section{Acknowledgments}

We are grateful to Jutta Conigliaro, Christian Schorpp, Philipp Klemm, Alexandra Stark, Claudia Pföhler, Thomas Vogt, Boris Kubuschok, Niels Murawski, Carsten Zwick, Silke Zinke (Berlin) and Harald Burkhardt (Frankfurt am Main), who helped in the collection of blood samples from the respective patients, including clinical data. We are also grateful to Pierre Simon, Bernhard Thurner and Jan Voswinkel (Paris), who proofread the manuscript and gave helpful advice. LT received a Saarland University fellowship.

\section{Author details}

'Department of Internal Medicine I, José Carreras-Center for Immuno- and Gene Therapy, University of Saarland Medical School, Kirrbergerstr., D-66421 Homburg, Saar, Germany. ${ }^{2}$ Institute of Medical Biostatistics, Saarland

University, Kirrbergerstr., D-66421 Homburg, Saar, Germany.

Received: 17 July 2013 Accepted: 22 November 2013

Published: 10 December 2013

\section{References}

1. Rahman P, Nguyen E, Cheung C, Schentag CT, Gladman DD: Comparison of radiological severity in psoriatic arthritis and rheumatoid arthritis. J Rheumatol 2001, 28:1041-1044.

2. Moll JM, Wright V: Psoriatic arthritis. Semin Arthritis Rheum 1973, 3:55-78.

3. Taylor W, Gladman D, Helliwell P, Marchesoni A, Mease P, Mielants H: Classification criteria for psoriatic arthritis: development of new criteria from a large international study. Arthritis Rheum 2006, 54:2665-2673.

4. Nograles KE, Brasington RD, Bowcock AM: New insights into the pathogenesis and genetics of psoriatic arthritis. Nat Clin Pract Rheumatol 2009, 5:83-91.

5. Peluso R, Lupoli GA, Del Puente A, lervolino S, Bruner V, Lupoli R, Di Minno MN, Foglia F, Scarpa R, Lupoli G: Prevalence of thyroid autoimmunity in patients with spondyloarthropathies. J Rheumatol 2011, 38:1371-1377.

6. Colmegna I, Sainz B Jr, Citera G, Maldonado-Cocco JA, Garry RF, Espinoza LR: Anti-20S proteasome antibodies in psoriatic arthritis. J Rheumatol 2008, 35:674-676.

7. Veale DJ, Barnes L, Rogers S, Fitzgerald O: Immunohistochemical markers for arthritis in psoriasis. Ann Rheum Dis 1994, 53:450-454.

8. Thurner L, Preuss KD, Fadle N, Regitz E, Klemm P, Zaks M, Kemele M, Hasenfus A, Csernok E, Gross WL, Pasquali JL, Martin T, Bohle RM, Pfreundschuh M: Progranulin antibodies in autoimmune diseases. J Autoimmun 2013, 42:29-38.

9. Butler GS, Dean RA, Tam EM, Overall CM: Pharmacoproteomics of a metalloproteinase hydroxamate inhibitor in breast cancer cells: dynamics of membrane type 1 matrix metalloproteinase-mediated membrane protein shedding. Mol Cell Biol 2008, 28:4896-4914.

10. Kessenbrock K, Fröhlich L, Sixt M, Lämmermann T, Pfister H, Bateman A, Belaaouaj A, Ring J, Ollert M, Fässler R, Jenne DE: Proteinase 3 and neutrophil elastase enhance inflammation in mice by inactivating antiinflammatory progranulin. J Clin Invest 2008, 118:2438-2447.

11. Suh HS, Choi N, Tarassishin L, Lee SC: Regulation of progranulin expression in human microglia and proteolysis of progranulin by matrix metalloproteinase-12 (MMP-12). PLoS One 2012, 7:e35115.

12. Bai XH, Wang DW, Kong L, Zhang Y, Luan Y, Kobayashi T, Kronenberg HM, Yu XP, Liu CJ: ADAMTS-7, a direct target of PTHrP, adversely regulates endochondral bone growth by associating with and inactivating GEP growth factor. Mol Cell Biol 2009, 29:4201-4219.

13. Baker M, Mackenzie IR, Pickering-Brown SM, Gass J, Rademakers R, Lindholm C, Snowden J, Adamson J, Sadovnick AD, Rollinson S, Cannon A, Dwosh E, Neary D, Melquist S, Richardson A, Dickson D, Berger Z, Eriksen J, Robinson T, Zehr C, Dickey CA, Crook R, McGowan E, Mann D, Boeve B, Feldman H, Hutton M: Mutations in progranulin cause t-negative frontotemporal dementia linked to chromosome 17. Nature 2006, 442:916-919.

14. Tang W, Lu Y, Tian QY, Zhang Y, Guo FJ, Liu GY, Syed NM, Lai Y, Lin EA, Kong L, Su J, Yin F, Ding AH, Zanin-Zhorov A, Dustin ML, Tao J, Craft J, Yin Z, Feng JQ, Abramson SB, Yu XP, Liu CJ: The growth factor progranulin binds to TNF receptors and is therapeutic against inflammatory arthritis in mice. Science 2011, 332:478-484.

15. Chen X, Chang J, Deng Q, Xu J, Nguyen TA, Martens LH, Cenik B, Taylor G, Hudson KF, Chung J, Yu K, Yu P, Herz J, Farese RV Jr, Kukar T, Tansey MG: Progranulin does not bind tumor necrosis factor (TNF) receptors and is not a direct regulator of TNF-dependent signaling or bioactivity in immune or neuronal cells. J Neurosci 2013, 33:9202-9213.

16. Jian J, Zhao S, Tian Q, Gonzalez-Gugel E, Mundra JJ, Uddin SM, Liu B, Richbourgh B, Brunetti R, Liu CJ: Progranulin directly binds to the CRD2 and CRD3 of TNFR extracellular domains. FEBS Lett 2013, 587:3428-3436.

17. Egashira Y, Suzuki Y, Azuma Y, Takagi T, Mishiro K, Sugitani S, Tsuruma K, Shimazawa M, Yoshimura S, Kashimata M, Iwama T, Hara H: The growth factor progranulin attenuates neuronal injury induced by cerebral 
ischemia-reperfusion through the suppression of neutrophil recruitment. J Neuroinflammation 2013, 10:105.

18. Kawase R, Ohama T, Matsuyama A, Matsuwaki T, Okada T, Yamashita T, Yuasa-Kawase M, Nakaoka H, Nakatani K, Inagaki M, Tsubakio-Yamamoto K, Masuda D, Nakagawa-Toyama Y, Nishida M, Ohmoto Y, Nishihara M, Komuro I, Yamashita S: Deletion of progranulin exacerbates atherosclerosis in ApoE knockout mice. Cardiovasc Res 2013, 100:125-133.

19. Sfikakis PP, Tsokos GC: Towards the next generation of anti-TNF drugs. Clin Immunol 2011, 141:231-235.

20. Bateman A, Bennett HPJ: The granulin gene family: from cancer to dementia. Bioessays 2009, 31:1245-1254.

21. Espevik T, Nissen-Meyer J: A highly sensitive cell line, WEHI 164 clone 13 , for measuring cytotoxic factor/tumor necrosis factor from human monocytes. J Immunol Methods 1986, 95:99-105.

22. Chapman PB, Lester TJ, Casper ES, Gabrilove JL, Wong GY, Kempin SJ, Gold PJ, Welt S, Warren RS, Starnes HF: Clinical pharmacology of recombinant human tumor necrosis factor in patients with advanced cancer. J Clin Oncol 1987, 5:1942-1951

23. Antoni C, Krueger GG, de Vlam K, Birbara C, Beutler A, Guzzo C, Zhou B, Dooley LT, Kavanaugh A, IMPACT 2 Trial Investigators: Infliximab improves signs and symptoms of psoriatic arthritis: results of the IMPACT 2 trial. Ann Rheum Dis 2005, 64:1150-1157.

24. Mease PJ, Kivitz AJ, Burch FX, Siegel EL, Cohen SB, Ory P, Salonen D, Rubenstein J, Sharp JT, Tsuji W: Etanercept treatment of psoriatic arthritis: safety, efficacy, and effect on disease progression. Arthritis Rheum 2004, 50:2264-2272

25. Mease PJ, Gladman DD, Ritchlin CT, Ruderman EM, Steinfeld SD, Choy EH, Sharp JT, Ory PA, Perdok RJ, Weinberg MA, Adalimumab Effectiveness in Psoriatic Arthritis Trial Study Group: Adalimumab for the treatment of patients with moderately to severely active psoriatic arthritis: results of a double-blind, randomized, placebo-controlled trial. Arthritis Rheum 2005, 52:3279-3289.

26. Ritchlin CT, Kavanaugh A, Gladman DD, Mease PJ, Helliwell P, Boehncke WH, de Vlam K, Fiorentino D, Fitzgerald O, Gottlieb AB, McHugh NJ, Nash P, Qureshi AA, Soriano ER, Taylor WJ, Group for Research and Assessment of Psoriasis and Psoriatic Arthritis (GRAPPA): Treatment recommendations for psoriatic arthritis. Ann Rheum Dis 2009, 68:1387-1394.

doi:10.1186/ar4406

Cite this article as: Thurner et al:: Progranulin antibodies entertain a proinflammatory environment in a subgroup of patients with psoriatic arthritis. Arthritis Research \& Therapy 2013 15:R211.

\section{Submit your next manuscript to BioMed Central and take full advantage of:}

- Convenient online submission

- Thorough peer review

- No space constraints or color figure charges

- Immediate publication on acceptance

- Inclusion in PubMed, CAS, Scopus and Google Scholar

- Research which is freely available for redistribution 